\title{
INGUINAL HERNIA IN FEMALE TWINS WITH SPECIAL REFERENCE TO THE IDENTIFICATION OF MONOZYGOTISM
}

BY

\author{
C. E. KELLETT, M.D., M.R.C.P.
}

It has long been common knowledge that certain twins resemble one another in a remarkable way. The fact that many more like sexed twins are born than the theoretical ratio $1: 2: 1$ would demand constitutes evidence in favour of the belief that such twins are monozygotic, for the actual figures of twin births can be adequately explained on the assumption that about one half the pairs of like sexed twins are monozygotic. Granted, however, the existence of monozygotic twins their recognition is far harder than is generally realized.

If Pliny mentions how ' Toranius a merchant slave-seller, sold unto Marcus Antonius (now one of the great Triumvirs) two most beautiful and sweet-faced boies, for twins, so like they were to one another, albeit the one was born in Asia, and the other beyond the Alpes,' the lesson has been slowly learnt, and in 1930 Stocks stated that it was 'surprising to find with what assurance many writers on the question of twins regard their own ability to diagnose the monozygotic from the dizygotic with certainty, which can only be explained by the fact that no satisfactory check has so far been devised as to whether the diagnosis was right or wrong.' The method that Stocks proposed has in addition to its other virtues this, that it is sufficiently precise to admit of such checking. In elaborating this method Stocks has himself made use of two checks : all opposite sexed twins must be dizygotic ; the ratio of monozygotic to dizygotic twins as determined by his method should agree with that required on the general statistical grounds already referred to. He came to the conclusion that facial resemblance is not a reliable criterion of monozygotism, and believes that finger-print resemblances between corresponding fingers in twins furnishes the best means of separating monozygotic from dizygotic twins. This depends on the criterion that monozygotic twins have six or more patterns alike on corresponding fingers of the same-sided hands, whilst dizygotic have six or less alike ; in the ambiguous case when six are alike the diagnosis is completed by comparing the differences in height and four simple head measurements with tabulated values. His definition of alikeness is confessedly rather vague, and is that to a 'casual examination they should appear the same,' though this 'casual examination' implies an examination that only just falls short of counting the ridges, and a very close resemblance. Though this method is probably the most clear cut of any at the clinician's disposal it should be noted that it is not claimed that it will ' lead to a correct diagnosis in every case, but the errors will not be frequent enough to invalidate conclusions arrived at by using the methods in statistical researches on groups of twins,' and that furthermore the very phrase 'casual examination' introduces a subjective factor. Moreover, 
this method did not actually completely satisfy Stock's own checks, since one, if not two, pairs of opposite sexed twins, and therefore certainly dizygotic, satisfied these criteria. He had on the other hand no means of showing whether monozygotic twins ever failed to satisfy them, and in this lies the chief interest of the following twins.

\section{Case report}

Annie and Isobella S. were brought to the Royal Victoria Infirmary, Newcastle-on-Tyne, in October 1936 because both of them had for the past two years symmetrical bilateral indirect inguinal herniae. They were just six years old, and country folk from the region of Berwick. Their mother was one of a family of seven ; one of her sisters had had twin daughters, now aged twenty-two ; apart from this she knew of no other twins in her family. So far as she knew there were no twins on her husband's side, nor did she know of any member of either side of the family having, or having had a rupture. Annie and Isobel were operated on by Mr. F. C. Pybus under whom they had been admitted on October 13, 1936; the diagnosis was in each case confirmed and a radical cure performed. As the photograph shows (fig. 1) the two children

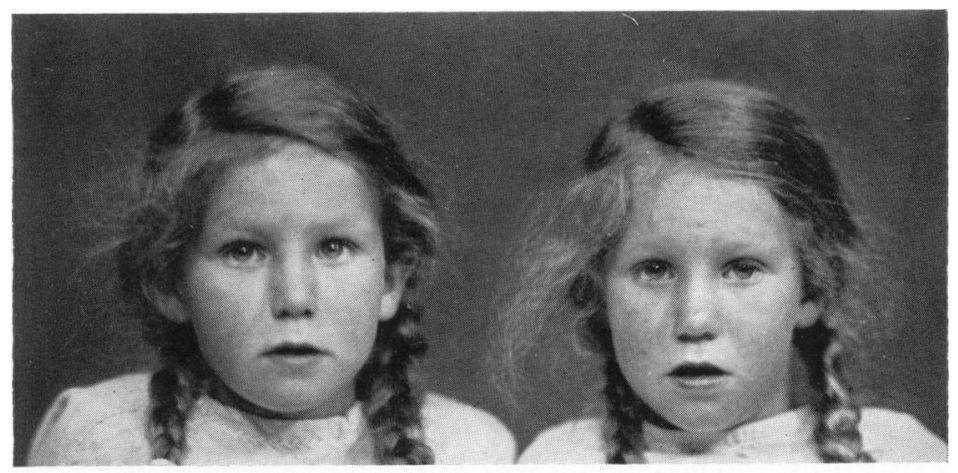

FIG. 1.

resembled one another closely. Table 1 gives certain measurements and fig. 2 details of their finger-prints, slightly enlarged.

TABLE 1

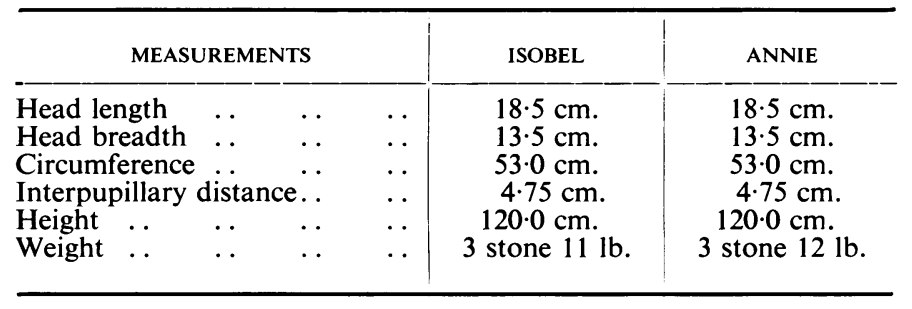

\section{Discussion}

Inguinal herniae are by no means rare ; it is therefore rather remarkable that there should be so few cases on record of herniae in identical twins. De 


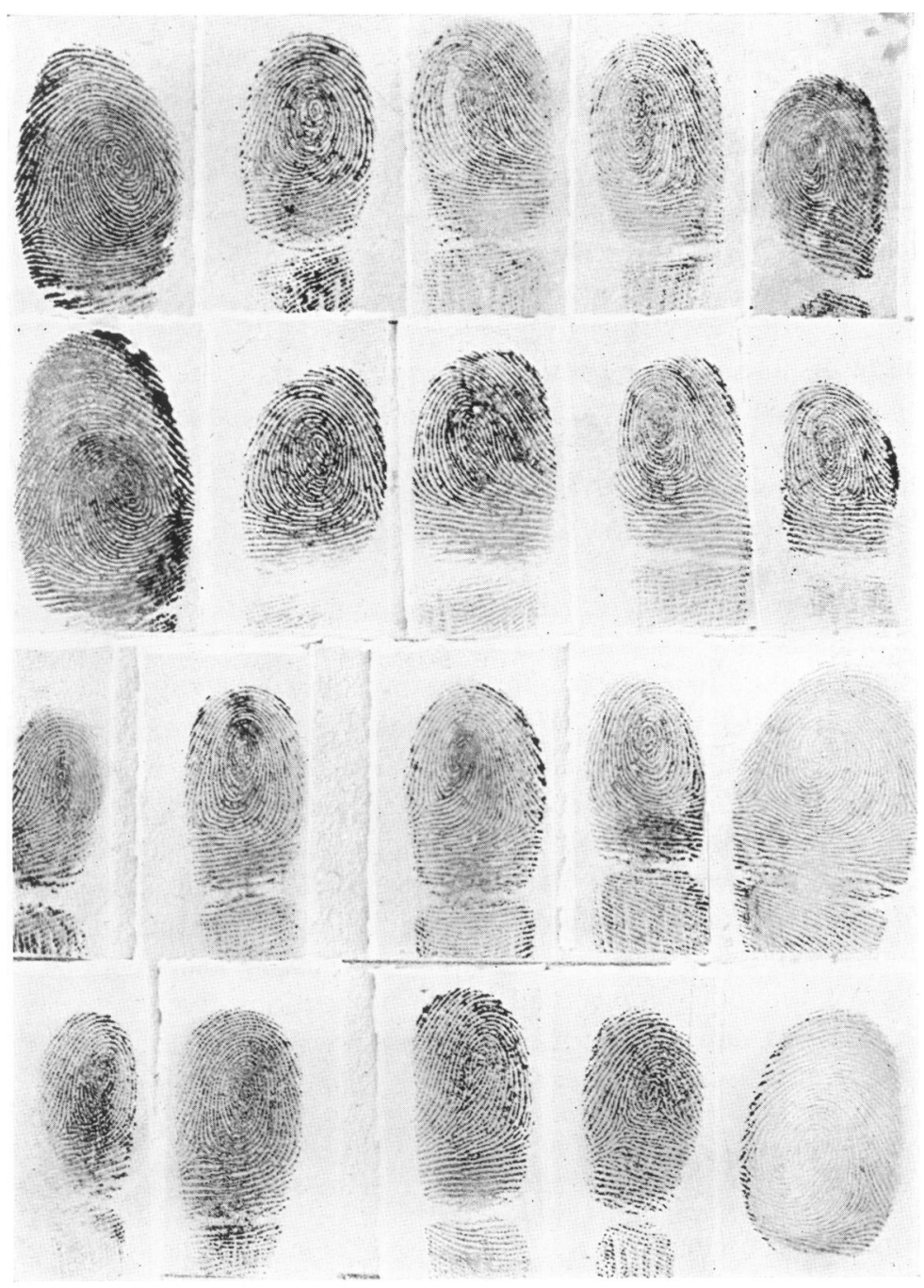

FIG. 2.

Lange, who reported a case of bilateral inguinal hernia in a pair of male twins five and a half months old in 1936, could find in the literature reference to only one other similar case ; the case here recorded would appear to constitute the third. Whereas it is probable that many cases of hernia in twins are not reported because of their relatively unexciting nature, these figures certainly suggest that twinning in itself does not predispose to rupture. In the absence of any known external cause it seems reasonable to suppose that, as is generally held, the cause of these children's ruptures was congenital; it should then be possible, given adequate figures, to determine the likelihood that these twins are dizygotic and ruptured by 'coincidence,' thus determining their value as a check. The relatively simple nature of their affliction and its common occurrence encouraged 
the belief that in this condition, if in no other, adequate figures would be forthcoming. In this we were to some extent disappointed, the best set of data being neither as modern nor as complete as might have been reasonably expected. None the less it is possible to make a rough estimate of the requisite probability, an estimate that may be expected to err on the right side. Such a statistical approach might have been vitiated had these children come of a stock peculiarly prone to rupture, or if there had been reason for supposing that twinning in itself was liable to lead to rupture ; the absence of any history of rupture in the family, together with the extremely few cases of rupture reported in twins appeared to dispose of these possible sources of error.

We have to estimate, supposing the twins dizygotic, the probability of the case being a 'coincidence,' i.e. the probability that the second child, who is (a) a dizygotic twin, and (b) also a female, should have developed, and be brought up for treatment for, a double inguinal hernia, between the ages of one and five.

The available statistical information is derived from the records of the London Truss Society as presented by J. Macready (1893), and from similar records made at the Bureau Central in Paris by P. Berger (1896). Unfortunately the two sets of statistics are seriously discordant in many respects. Berger has explained some of the discrepancies as due to differences in the manner of collection of the records, but it is difficult to trace the origin of the others. Another essential piece of information comes from the records of medical examinations of conscripts in Paris (Berger, 1896), which show that in the (census) year 1881 the proportion of conscripts judged unfit for full service on account of hernias was one in seventy-eight. Similar examinations in other places have given both higher and lower proportions than this. We shall, however, take this value, since for our purpose it would suffice to deal only with the more obvious cases of hernia.

We shall write :

$\mathrm{h}=$ number of females in age-group one to four brought to be treated for double inguinal hernia.

$\mathrm{f}=$ number of females in this age-group of the population,

$\mathrm{H}=$ number of men in age-group twenty to twenty-four presenting themselves to be treated for hernia,

$\mathbf{P}=$ proportion of males in this age-group rendered not wholly fit by hernia, $\mathbf{M}=$ number of males in this age-group of the population,

$\mathrm{p}=$ proportion of females in age-group one to four requiring treatrient for double inguinal hernia.

We have already seen that we may take $1 / 78$ as an estimate for $P$; the numerical values of the other quantities can be supplied by Berger's or by Macready's statistics.

We seek first the proportion of people in the population unfitted by hernia that presented themselves for treatment (at the Truss Society or at the Bureau Central), supposing with Berger that this proportion is the same (at least approximately) for both sexes and all ages. The proportion can then be determined by considering men of the age-group twenty to twenty-four; it is plainly $\mathrm{H} / \mathrm{MP}$. Therefore the number of females unfitted by hernia in the age-group 
one to four of the population must equal $\mathrm{hMP} / \mathrm{H}$. Lastly, this number bears to the number $\mathrm{f}$ of females in this age-group the proportion $\mathrm{p}=\mathrm{hMP} / \mathrm{Hf}$.

Using Berger's statistics * we have, in round figures, $h=4, f=75,000$, $\mathrm{H}=200, \mathrm{P}=1 / 78, \mathrm{M}=147,000$.

These give for $p$ the value $(4 \times 147,000) /(78 \times 200 \times 75,000)=0.00050$, or, 1 in 2,000 .

Using Macready's statistics $\dagger$ we find $h=18, f=1,377,000, H=975$, $M=1,115,000$, the population figures, which here refer to England and Wales, being taken from the Registrar-General's Report on the census of 1881. It is clear from the (less detailed) figures given for London that we shall commit at the worst an error of about 10 per cent. by using the figures for the whole country. We now get for $p$ the estimate $(18 \times 1,115,000) /(78 \times 975 \times 1,377,000)$ $=0.00019$ or slightly less than 1 in 5,000 .

Thus the estimates suggest that the chances are some thousands to one against the present case having arisen by coincidence. This suggests strongly indeed that these children are monozygotic, but as shown in fig. 2, not more than five pairs of their finger prints are similar; a view confirmed by Dr. P. Stocks (1938) himself, who, on that evidence alone, would have concluded that the probability of their 'being monozygotic was small though not zero.' $\mathrm{He}$ continues: 'I have met with a few twin pairs having only four or five similar prints who appeared from other physical resemblances to be monozygotic, and I think one can only say that in such cases the pair is much more likely to be dizygotic than monozygotic.'

In the present case we have seen that the chances of the twins resembling each other in having the type of hernia in question at about the same age 'by coincidence' are probably less than 1 in 1,000 : whereas the chances of dizygotic female twins-or of any pair of sisters-having facial or other physical resemblances can hardly be of this order of smallness. Hence it seems safe to conclude that in this instance the clinical evidence outweighs the comparative lack of similarity in the finger prints, and that therefore, at least in exceptional cases, monozygotic twins may have not more than five pairs of finger prints ' similar.'

This pair, which may be compared with a known dizygotic like-sexed pair described elsewhere (Kellett, 1933), constitute then a helpful check on Stock's method, and we believe with him that 'it is only by the laborious collection of such cases that the real probabilities of different degrees of finger-print similarity can be assessed in the two varieties of twins.'

I am much indebted to Mr. F. C. Pybus, M.S., F.R.C.S., under whose care these twins have been, to Dr. H. P. Mulholland, M.A., Ph.D., of the Department of Mathematics, King's College, The University of Durham, who is responsible for the calculations of probability, and to Dr. Percy Stocks of the General Register Office, Somerset House, London, for all the help they have given me.

* Loc. cit., pp. 77, 84, 85, and 103. The figures for $\mathrm{M}$ and $\mathrm{f}$ refer to the population in the Department of the Seine; the latter has been estimated on the basis of the figure given by Berger for Paris.

$\dagger$ Loc. cit., pp. 6, 7, and 249 . We have neglected some of the rare types mentioned elsewhere by the author. Moreover, $\mathrm{h}$ is estimated to be 18 on the basis of the author's figure for the age-group one to five. 


\section{REFERENCES}

Berger, P. (1896). Résultats de l'examen de dix mille observations de hernies, Paris. Kellett, C. E. (1933). Arch. Dis. Childh., 8, 279.

De Lange, Cornelia (1936). Ibid., 11, 39.

Macready, J. F. C. H. (1893). A Treatise on Ruptures, London.

Plinius Secundus, C. (1601). The Historie of the World, Philemon Holland's Translation, London, p. 162.

Stocks, P. (1930). Ann. Eugen., 4, 49. (1938). Personal communication. 